\title{
Erratum to: Collaborative fractal-based supply chain management based on a trust model for the automotive industry
}

\author{
Seungjin Oh • Kwangyeol Ryu • Ilkyeong Moon • \\ Hyunbo Cho $\cdot$ Mooyoung Jung
}

Published online: 28 May 2011

(C) Springer Science+Business Media, LLC 2011

\section{Erratum to: Flex Serv Manuf J (2010) 22:183-213 DOI 10.1007/s10696-011-9082-7}

The phrase "and Pusan National University Research Grant, 2008" was not included in the Acknowledgments section of the Original Publication.

The complete Acknowledgments should read "This research was supported by the Basic Science Research Program through the National Research Foundation of Korea (NRF) funded by the Ministry of Education, Science, and Technology (20090077660 and 2009-0087861), and Pusan National University Research Grant, 2008. The authors would like to express their gratitude for this support. We also thank the editor and anonymous reviewers for their helpful comments."

The online version of the original article can be found under doi:10.1007/s10696-011-9082-7.

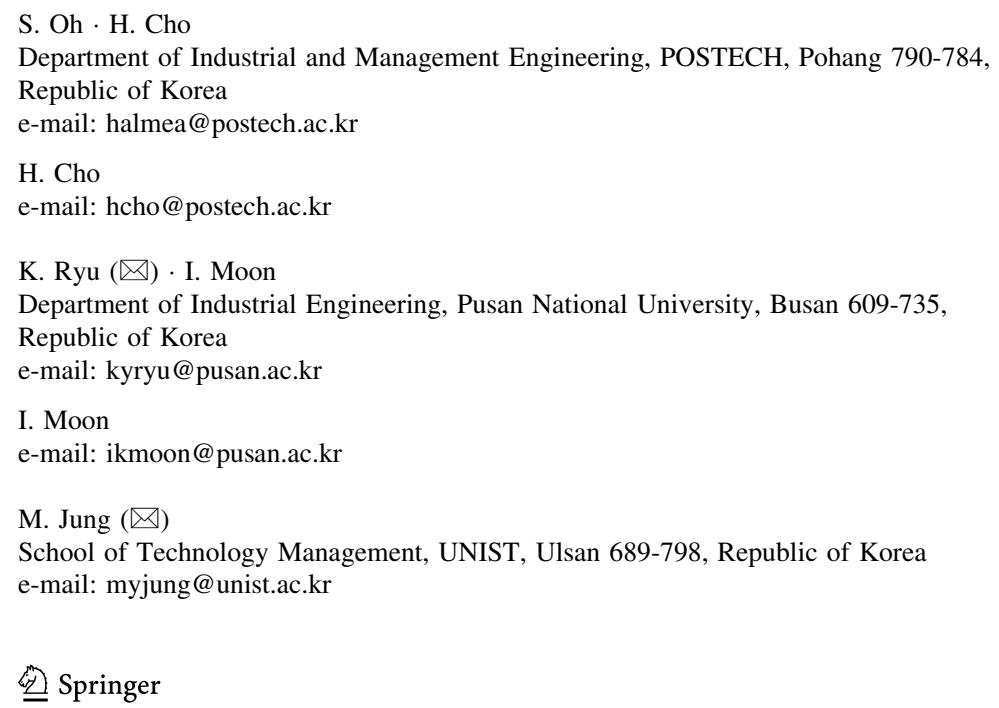

